\title{
Prevention of Type 2 (non-insulin-dependent) diabetes mellitus by diet and physical exercise
}

\section{The 6-year Malmö feasibility study}

\author{
K.-F. Eriksson and F. Lindgärde \\ Department of Internal Medicine, Section of Preventive Medicine, Malmö General Hospital, University of Lund, Malmö, Sweden
}

\begin{abstract}
Summary. From a previously reported 5 -year screening programme of 6,956 47-49-year-old Malmö males, a series of 41 subjects with early-stage Type 2 (non-insulin-dependent) diabetes mellitus and 181 subjects with impaired glucose tolerance were selected for prospective study and to test the feasibility aspect of long-term intervention with an emphasis on life-style changes. A 5-year protocol, including an initial 6months (randomised) pilot study, consisting of dietary treatment and/or increase of physical activity or training with annual check-ups, was completed by $90 \%$ of subjects. Body weight was reduced by $2.3-3.7 \%$ among participants, whereas values increased by $0.5-1.7 \%$ in non-intervened subjects with impaired glucose tolerance and in normal control subjects $(p<0.0001)$; maximal oxygen uptake $\left(\mathrm{ml} \cdot \mathrm{min}^{-1} \cdot \mathrm{kg}^{-1}\right)$ was increased by $10-14 \%$ vs decreased by $5-9 \%$, respectively $(p<0.0001)$. Glucose tolerance was normalized in $>50 \%$ of subjects with impaired glucose tolerance, the accumulated
\end{abstract}

incidence of diabetes was $10.6 \%$, and more than $50 \%$ of the diabetic patients were in remission after a mean follow-up of 6 years. Blood pressure, lipids, and hyperinsulinaemia were reduced and early insulin responsiveness to glucose loading preserved. Improvement in glucose tolerance was correlated to weight reduction $(r=0.19, p<0.02)$ and increased fitness $(r=0.22, p<0.02$ ). Treatment was safe, and mortality was low (in fact $33 \%$ lower than in the remainder of the cohort). We conclude that long-term intervention in the form of diet and physical exercise is feasible even on a large scale, and that substantial metabolic improvement can be achieved which may contribute to prevent or postpone manifest diabetes.

Key words: Impaired glucose tolerance, Type 2 (non-insulindependent) diabetes mellitus, oral glucose tolerance test, insulin, long-term intervention, diet, physical exercise.
Diabetes mellitus and its complications constitute a major health problem in modern societies $[1,2]$. Type 2 (non-insulin-dependent) diabetes is associated with an increased frequency of cardiovascular risk factors [3] and subsequent cardiovascular disease and mortality [4-6]; and in the agegroup under consideration here, the expected reduction in lifespan is 5-7 years [4]. In previous studies, annual progression rates from impaired glucose tolerance (IGT) to Type 2 diabetes of 2-3\% have been found [7-9], though the causal link with known risk factors remains unclear [10]. Further preventive studies, with an emphasis on life-style changes, e. g., diet and physical exercise, are needed [11-13]. Apart from the fact that the efficacy of oral agents in preventing Type 2 diabetes and its sequelae has yet to be established [13], non-pharmacological treatment is an approach of great importance, not only vis-á-vis glucose metabolismbut also vis-á-vis the overall metabolic profile $[14,15]$.

We have previously reported on studies where 6-12month periods of dietary treatment or physical training (or both) were found to be beneficial in cases of IGT or mild Type 2 diabetes [16-19], but the chief concern is whether these treatment programmes can be satisfactorily extended over longer periods [20], and drop-out minimised. Here we report how this was achieved in a simple and generally applicable manner in a large series of middle-aged males with Type 2 diabetes $(n=41)$ or IGT ( $n=181$ ), and on the metabolic impact of such a long-term intervention programme as reflected in consecutive oral glucose tolerance test (OGTT) results and values for blood pressure and lipids. The study has its origins in two age-cohort screening programmes carried out in the period 1974-1985, in the city of Malmö in the southernmost province of Sweden $[21,22]$.

\section{Subjects and methods}

\section{Study population}

In a 5-year health screening survey of 6,956 47-49-year-old Malmö males ( $48.1 \pm 0.7$ years; mean $\pm \mathrm{SD}$ ) [21], an OGTT was included. After $6.2 \pm 0.9$ years $(54.3 \pm 1.4$ years $)$, a second 3 -year screening 
survey was performed on 5,149 of the participants in the first screening.

At the first screening Type 2 diabetes was diagnosed [23] in 81 cases, and 260 cases with normal (i. e. $\leq 6.7 \mathrm{mmol} / \mathrm{l}$ ) fasting glucose values (capillary whole blood), but 2 -h glucose values in the 7.0 $11.0 \mathrm{mmol} / \mathrm{l}$ range on screening OGTT and on a repeat test within a month, were designated as IGT [21]. Diabetic subjects with gross hyperglycaemia or symptoms were referred to the diabetes clinic, and some already under medical care were referred to their own physician. Mild (no symptoms) Type 2 diabetic subjects (Group 1) were referred to the "borderline diabetes clinic" and enrolled in the intervention programme. With a few exceptions, all IGT patients were invited to further examination and treatment, but based on ranking of intercorrelating variables referred to only one of the out-patient clinics at the department. Thus, 181 patients (Group 2) were enrolled in the diabetes prevention programme, and 79 not (Group 3). In addition, a normal control group (Group 4) was studied.

\section{Treatment groups $1-2$}

Group 1 consisted of 41 patients with newly-detected Type 2 diabetes of whom 39 attended a check-up after 5 years of treatment (second screening). Five patients were already on medication for hypertension at the outset.

Of the 181 consecutive IGT subjects enrolled in the programme (Group 2), 161 attended the 5-year treatment follow-up; 27 subjects were on antihypertensive medication at the outset.

\section{Comparison groups 3-4}

The 79 non-randomised subjects with IGT (Group 3), who for various reasons were not enrolled in the programme, were informed about their condition either at the clinic or by letter. Although they received no specific diabetes prevention treatment at the clinic, most of them underwent intervention in some form. Twenty subjects were referred to the hypertension out-patient clinic, 20 were further examined to evaluate alcohol consumption (including long-term check-ups), 17 were referred to their own or another physician for further check-ups, and another 22 either failed to attend at the outpatient clinics, declined further check-ups or had moved out of the district. This group (3) is included to complete the picture of IGT in the cohort. Mean glucose values for the group were identical to those of Group 2 (2-h glucose $8.4 \pm 1.1$ vs $8.2 \pm 1.0$ mmol $/$; mean $\pm S D$; NS), and except for a small difference in blood pressure no other differences were found in baseline variables. Fifty-six members of the group attended the follow-up at the second screening. Fourteen subjects were already on medication for hypertension at the outset.

In 114 randomly selected subjects (Group 4) with strictly normal OGTT (fasting $<6.7 \mathrm{mmol} / \mathrm{l}$ and $2 \mathrm{~h}<7.0 \mathrm{mmol} / 1$, drawn from the 5,347 subjects at the first screening), ergometry was included in both screenings.

\section{Methods}

Details of the screening procedure and methods used have been reported previously $[21,22]$. An oral glucose load of $30 \mathrm{~g}$ glucose $/ \mathrm{m}^{2}$ body surface area was used (NB, the study was started before the World Health Organization (WHO) standardisation, but results are comparable to those obtained with the WHO standard 75-g load [24]), and blood samples were taken both at fasting and at 40 and 120 min post-load, capillary whole blood glucose being analysed with a hexokinase method [25] and plasma insulin with a radioimmunoassay [26]. Serum cholesterol and plasma triglycerides were measured with standard methods. Body mass index (BMI) was calculated from body weight and height $\left(\mathrm{kg} / \mathrm{m}^{2}\right)$. Triceps skinfold was measured with Harpenden callipers over the middle of the upper arm, values being subjected to logarithmic transformation [27]. Blood pressure was measured with the subject recumbent after 10 min rest.
Maximal oxygen untake was estimated as described by Åstrand [28] from heart response to a given submaximal workload (i.e. 50$150 \mathrm{~W}$, depending on weight and reported physical activity), using a bicycle ergometer (Monark, Varberg, Sweden) and recorded at steady-state with a heart rate of $\geq 120$ beats $/ \mathrm{min}$. This estimation procedure is also appropriate for IGT cases [29]. Ergometry was not generally performed in subjects reporting heart symptoms or undergoing treatment with beta-blockers or antiarrhythmic drugs.

\section{Intervention procedure}

The screening activity and work at the different clinics at the Department of Preventive Medicine are integrated on the same floor of a building located close to the main hospital complex. The intervention programme at the "borderline diabetes clinic", previously described $[16,17,19]$, included dietary advice and increase of physical activity. Investigation rooms, laboratory, lecture room and training halls were all housed in the same building. For the main work at the clinic, a qualified full-time nurse and a part-time dietician, physiotherapist, secretary and physician were engaged, who together represent approximately $1 / 6$ of the staff resources at the department. Screening investigations were free of charge, but a small charge is levied for treatment at the clinics.

At first attendance at the borderline clinic, subjects found to be otherwise healthy (i.e. apart from minor, unconnected ailments or mild hypertension) were invited to participate in a long-term organised programme with consecutive testing (i. e. $6,12,18,24,36,48$ and 60 months after enrollment, and 2-3 days after the latest training session) including OGTT, weight control and ergometry. Of those who were eligible, $95 \%$ accepted the invitation to participate. The subjects were offered the choice of group-wise participation (10-15 to a group) or following the protocol on their own after initial instruction. There was a small variation in the number of subjects at the intervening check-ups but at least $80 \%$ attended each check-up and (except for drop-outs) no subject missed more than one. The follow-up after five years in treatment formed part of the second screening programme (after a mean period of 6 years), and was performed in the same month of the year as the baseline test (if possible). For all participants, every OGTT was followed by an appointment with the same physician (K.-F. Eriksson) for examination and to be given information about their results. If glucose values were found to have increased significantly, the participant was given check-ups at shorter intervals. In some subjects with completely normalized OGTT, the 4-year check-up was omitted. All participants were kept informed as to the risk of future diabetes and any possibly diabetes-related macrovascular complications. Smokers were generally advised to stop or at least reduce smoking.

Eighteen participants from Group $1(44 \%)$ and 68 from Group 2 $(38 \%)$ followed the protocol as organised groups, with a 6-month period of supervised physical training followed by a 6 -month period of dietary treatment, or vice versa. After 12 months all participants continued to follow the protocol, with both diet and training, either on their own or together with previous group partners (one group underwent supervised training for a total of 18 months), and some groups continued training at local sports clubs. Those who did not participate in group sessions followed the protocol on their own after initial instruction, attending for check-ups at the same intervals as the groupwise participants. The attendance rate was comparable in both categories. In 23 randomised IGT or Type 2 diabetes subjects, final selection for enrollment in the intervention programme was postponed for 6 months, mean 2-h glucose being unchanged on retesting.

\section{Statistical analysis}

The paired $t$-test was used to test within-group changes (\%) and analysis of variance (ANOVA) to test between-group differences of these changes, Bonferroni's $t$-test being used to test differences $(5 \%$ level) between groups if significant F-values $(p<0.05)$ were obtained (Table 1). The $\mathrm{Chi}^{2}$ test was used to compare frequencies be- 
Table 1. Baseline characteristics and differences (\%) at 6-year follow-up by Groups 1-4

\begin{tabular}{|c|c|c|c|c|c|}
\hline & $\begin{array}{l}\text { At baseline } \\
\text { At follow-up }\end{array}$ & $\begin{array}{l}\text { Group } 1 \\
\text { (Type } 2 \text { diabetes) } \\
n=41 \\
n=39\end{array}$ & $\begin{array}{l}\text { Group } 2 \\
(\text { IGT) } \\
n=181 \\
n=161\end{array}$ & $\begin{array}{l}\text { Group } 3 \\
\text { (IGT) } \\
n=79 \\
n=56\end{array}$ & $\begin{array}{l}\text { Group } 4 \\
\text { (control) } \\
n=114 \\
n=114\end{array}$ \\
\hline Triceps skin-fold index & $\begin{array}{l}\mathrm{B} \\
\mathrm{D}\end{array}$ & $\begin{array}{c}202 \pm 18 \\
-3.9 \pm 9.0^{\mathrm{a}}\end{array}$ & $\begin{array}{l}203 \pm 18 \\
-5.8 \pm 8.0^{c}(4)\end{array}$ & $\begin{array}{c}205 \pm 18 \\
-3.9 \pm 13.5\end{array}$ & $\begin{aligned} & 195 \pm 18 \\
- & 2.3 \pm 7.7^{b}(2)\end{aligned}$ \\
\hline Systolic BP & $\begin{array}{l}\mathrm{B} \\
\mathrm{D}\end{array}$ & $\begin{array}{c}140 \pm 17 \\
-7.2 \pm 12.2^{\mathrm{b}}\end{array}$ & $\begin{array}{c}137 \pm 16 \\
-6.4 \pm 14.0^{\circ}\end{array}$ & $\begin{array}{c}144 \pm 24 \\
-6.2 \pm 18.0^{\mathrm{a}}\end{array}$ & $\begin{array}{l}127 \pm 12 \\
-\quad 3.0 \pm 10.5^{b}\end{array}$ \\
\hline Diastolic BP & $\begin{array}{l}\mathrm{B} \\
\mathrm{D}\end{array}$ & $\begin{array}{c}92 \pm 10 \\
-6.3 \pm 11.3^{b}\end{array}$ & $\begin{array}{c}92 \pm 10 \\
-5.4 \pm 10.0^{c}(4)\end{array}$ & $\begin{array}{c}96 \pm 13 \\
-7.2 \pm 12.2^{c}(4)\end{array}$ & $\begin{array}{c}86 \pm 8 \\
-\quad 1.3 \pm 9.8(2-3)\end{array}$ \\
\hline $\begin{array}{l}\text { Medication for } \\
\text { hypertension (\%) }\end{array}$ & $\begin{array}{l}B \\
D^{d}\end{array}$ & $\begin{array}{l}12.2 \\
20.6(2,4)\end{array}$ & $\begin{array}{l}14.9 \\
7.4(1,3-4)\end{array}$ & $\begin{array}{l}17.7 \\
23.9(2,4)\end{array}$ & $\begin{array}{l}0.9 \\
0.0(1-3)\end{array}$ \\
\hline
\end{tabular}

Group values are presented as means $\pm \mathrm{SD}$, for baseline $(B)$ data as absolute values and for follow-up data as \% -age difference $(D)$ from baseline values. ${ }^{\mathrm{a}} p<0.05 ;{ }^{\mathrm{b}} p<0.01 ;{ }^{\mathrm{c}} p<0.001$ for within-group differences (paired $t$-test). Figures in parentheses indicate groups with significantly $(p<0.05)$ different values for $\%$-age change from

tween groups. Student's $t$-test and the Wilcoxon test (insulin values) were used to test differences between means for the two comparable IGT groups ( 2 and 3 ). The Wilcoxon's matched-pairs signed rank test was used in Figure 2.

\section{Results}

\section{Baseline characteristics}

A trend of increasing obesity, poor physical fitness, high blood pressure (including medication for hypertension) and high lipid values (Table 1 and Fig. $1 \mathrm{~A}-\mathrm{B}$ ) was found in conjunction with IGT and Type 2 diabetes (all subjects were of the same age). 2-h insulin values (Fig.1D) increased substantially from those of normal control subjects (4) to those in the IGT groups (2 and 3 ), whereas those in the Type 2 diabetes group (1) showed no further increase (i.e. having already reached their maximum). Moreover, the insulin increment at $40 \mathrm{~min}$ post-load (Fig.2) was substantially (69\%) lower in the Type 2 diabetes group (1) than in the normal control group (4), whereas the IGT groups ( 2 and 3 ) both had intermediate values. As group allocation was based on glucose values, the baseline values were not subjected to ANOVA; instead, the two IGT groups were compared, the only difference between them being a somewhat higher blood pressure in the non-randomised reference group (3).

\section{Drop-out, withdrawal}

One participant $(2.5 \%)$ from the Type 2 diabetes group (1) was withdrawn and one died $(2.5 \%)$, and another three participants interrupted the intervention pro- baseline. If parentheses are missing in a whole row, the F-value the analysis of variance was $\geq 0.05$. ${ }^{\mathrm{d}} p<0.05$ for $\mathrm{Chi}^{2}$ between groups within parentheses. Groups 1 and 2, treatment groups; Groups 3 and 4 , comparison groups. $I G T$, impaired glucose tolerance; $B P$, blood pressure

gramme at some stage but attended at follow-up and their data are included. In the IGT group (2) four participants died $(2.2 \%)$, and two participants who moved away from the district and two who switched to other medical care $(2.2 \%)$ terminated check-ups. Another twelve participants $(6.6 \%)$ were drop-outs and failed to respond to further invitations. Four participants who were referred to (or were receiving) other medical care, and six who interrupted the programme at some stage $(5.5 \%)$, attended at follow-up and their data are included. There were no significant differences in the main baseline values between those who died, dropped out or interrupted the programme and the 151 participants in the IGT group (2) who completed the whole 5-year programme. Of the IGT non-randomised reference group (3) who were not treated at the "borderline clinic", 17 $(21.5 \%)$ failed to respond to the follow-up invitation, and six $(7.6 \%)$ died, but there were no differences in baseline values between responders and non-responders (including those who died).

\section{Follow-up data over 6 years}

The main purpose of Figures $1 \mathrm{~A}-\mathrm{D}$ is to show the trend during the first two years (first period), and from the 2year to the 5-year treatment follow-up (second period). The treatment period was at least 5 years and the 5-year treatment follow-up coincided with the second screening 6 years after the start of the study. (Minor irregularities in the curve are due to small differences in the number of subjects at check-ups). Mean percentage differences from baseline to the end of the study are given in the text. 

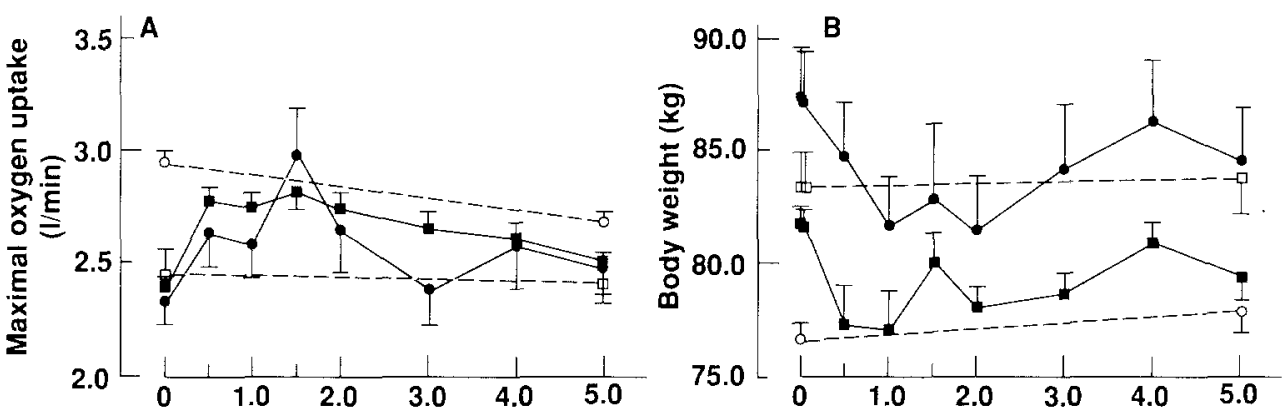

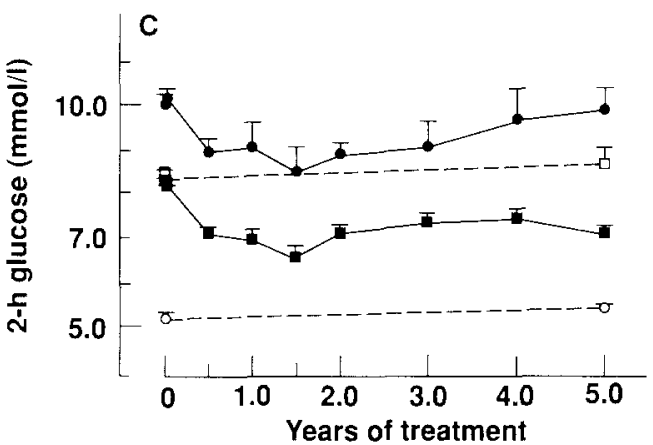

Fig. 1A-D. Figures 1A-D show baseline and follow-up values (mean $\pm \mathrm{SE}$ ) of the principal variables for groups 1-4, treatment groups $1-2(-)$; comparison groups $3-4(--)$, and in addition values for intervening check-ups in groups 1-2 (5 years in treatment coincide with the second screening after 6 years). denote Group 1 , Type 2 (non-insulin-dependent) diabetic subjects; $n=41 ; n=39$; (baseline; follow-up); $\mathbf{m}$, Group 2 (impaired glucose tolerance (IGT) subjects; $n=181 ; n=161$ ); $\square$, Group 3 (IGT non-randomised reference subjects; $n=79 ; n=56$ ); $O$, Group 4 (normal

\section{Development of oxygen uptake (Fig. 1 A)}

The development of maximal oxygen uptake ( $1 / \mathrm{min})$ within the four groups during the intervention period is shown in Figure $1 \mathrm{~A}$. In the treatment groups, including all cases where ergometry was performed (irrespective of whether physical exercise was started or not), a substantial increase of oxygen uptake was achieved during the first $6-12$ months $(9 \%, p<0.01$, in Group 1 with diabetic patients and $17 \%, p<0.001$, in Group 2 with IGT cases).

The increase for those who started physical training was even more pronounced, $20-25 \%$ during the first 612 months. After 18 months mean group values reached the level found for the normal control subjects (Group 4). The increase in oxygen uptake was maintained for 2 years, thereafter following the age-related decline found in normal control subjects, though the difference was now much smaller. As compared with their baseline values, after 6 years the treatment Groups 1 and 2 still had significantly higher $(14 \%, p<0.03 ; 8 \%, p<0.002)$ values for oxygen uptake $(1 / \mathrm{min})$, whereas the other groups, 3 and 4 had lower values ( $2 \%$, NS and $8 \%, p<0.001$, respectively), the difference in development between the treatment groups and the two other groups being highly significant $(p<0.0001)$. Similar changes in values were found when oxygen uptake was calculated according to body weight (Table 1). Sixty-five percent of the participants in the Type 2 diabetes group (1) and $47 \%$ of those in the IGT group (2) still manifested improved oxygen uptake 6 years later. By way of comparison, in a random 340 -subject sample from one birth-year cohort attending the second health screening (mean age, 55 years), mean oxygen uptake was $2.30 \pm 0.59 \mathrm{l} / \mathrm{min}$ or $29.9 \pm 7.0 \mathrm{ml} \cdot \mathrm{min}^{-1} \cdot \mathrm{kg}^{-1}$.

\section{Development of body weight (Fig. $1 B$ )}

A great reduction in body weight or body mass index was achieved during the first period, with a mean peak reduction of more than $6 \mathrm{~kg}$ at the end of the first year. During the second period, some of the weight reduction was lost, but mean body weight stabilized at a lower level than the baseline value. At the 5-year treatment follow-up, mean weight reduction was $2.0-3.3 \mathrm{~kg}$ in the Type 2 diabetes and IGT groups, whereas there was an increase of $0.2-2 \mathrm{~kg}$ in Groups 3 and 4 . Like the different development in oxygen uptake, this difference is also highly significant $(p<0.0001), 82 \%$ of those in the Type 2 diabetes group (1) and $71 \%$ of those in the IGT group (2) having maintained an overall weight reduction over 5 years. In groups 1 and 2, mean body weight was 5-6 kg (6-7\%) higher among those on antihypertensive treatment than among those not, both at baseline and at follow-up, whereas the weight reduction in the two sub-categories was comparable. 
Table 2. Results of the second screening (6-year follow-up) oral glucose tolerance test by Groups 1-4

\begin{tabular}{lllll}
\hline \multicolumn{5}{c}{$\begin{array}{l}\text { Outcome of oral glucose tolerance tests } \\
\text { at follow-up }\end{array}$} \\
\cline { 2 - 5 } & $\begin{array}{l}0^{\prime} \geq 6.7 \\
\text { and/or }\end{array}$ & $\begin{array}{l}0^{\prime}<6.7 \\
\text { and }\end{array}$ & $\begin{array}{l}0^{\prime}<6.7 \\
\text { and }\end{array}$ & $0^{\prime}<6.7$ \\
& 2 -h $\geq 11.1$ & 2 -h 7.8-11.0 & 2-h 7.0-7.7 & 2-h $<7.0$ \\
\hline Group 1 $(n=39)$ & $18^{\mathrm{a}}$ & 10 & 2 & 9 \\
(Type 2 diabetes) & $(46.2 \%)$ & $(25.6 \%)$ & $(5.1 \%)$ & $(23.1 \%)$ \\
Group 2(n=161) & $17^{\mathrm{b}}$ & 33 & 27 & 84 \\
(IGT) & $(10.6 \%)$ & $(20.5 \%)$ & $(16.8 \%)$ & $(52.2 \%)$ \\
Group 3 $(n=56)$ & $12^{\mathrm{a}}$ & $19^{\mathrm{c}}$ & 5 & $20^{\mathrm{c}}$ \\
(IGT) & $(21.4 \%)$ & $(33.9 \%)$ & $(8.9 \%)$ & $(35.7 \%)$ \\
Group 4 $(n=114)$ & 0 & 6 & 2 & 106 \\
(control) & $(0 \%)$ & $(5.3 \%)$ & $(1.8 \%)$ & $(93.0 \%)$ \\
Sum & 47 & 68 & 36 & 219 \\
(n=370) & $(12.7 \%)$ & $(18.4 \%)$ & $(9.7 \%)$ & $(59.2 \%)$ \\
\hline
\end{tabular}

${ }^{\mathrm{a}} n=2 ;{ }^{\mathrm{b}} n=3$ cases on drug treatment for diabetes; ${ }^{\mathrm{c}} n=2$ cases on dietary treatment for diabetes. $I G T$, impaired glucose tolerance. Groups 1 and 2, treatment groups; Groups 3 and 4, comparison groups

\section{2 h glucose (Fig. 1 C)}

Figure $1 \mathrm{C}$ shows mean group values for 2 -h glucose obtained at the annual OGTT. The Type 2 diabetes and IGT groups ( 1 and 2) manifested substantial improvement in glucose tolerance during the first 2-year intervention period, paralleled by the increase in oxygen uptake and reduction of body weight already mentioned. The improvement was maintained throughout the study period in the IGT group (2); 2 -h glucose decreased from $8.2 \pm 1.0$ (mean $\pm \mathrm{SD}$ ) atbaseline to $7.1 \pm 2.2 \mathrm{mmol} / \mathrm{l}(-13 \%)$ at follow-up; $p<0.0001)$ whereas mean 2-h glucose was essentially unchanged in the Type 2 diabetes group (1) (10.0 \pm 2.0 vs $9.9 \pm 3.3 \mathrm{mmol} / \mathrm{l}, \mathrm{NS}$ ) at follow-up (NB, some diabetic subjects being diagnosed according to their fasting glucose values, while their 2-h values were just below the cut-point for the 2 -h value). In stepwise regression analysis performed in the IGT group, changes in oxygen uptake ( $1 / \mathrm{min}$ ) and in body weight (differences from baseline to follow-up after 6 years) were found to be independently correlated to changes in 2-h glucose, the partial coefficients $\left(r^{2}\right)$ being $0.05(p<0.011)$ for oxygen uptake and $0.04(p<0.03)$ for body weight. In the $79 \%$ of cases with baseline oxygen uptake below the mean value in the normal control group (4) (i.e. $2.94 \mathrm{l} / \mathrm{min}$ ), the corresponding coefficients were 0.08 $(p<0.006)$ and $0.07(p<0.008)$. Glucose tolerance deteriorated in the IGT non-randomised reference group (3) (fasting values increased by $12 \%, p<0.002$ and 2 -h values by $3 \%, N S$ ), whereas the 2 -h value was unchanged in the normal control subjects (Group 4).

\section{2-h insulin values and increment at 40 min (Figs. $1 \mathrm{D}$ and 2)}

In the Type 2 diabetes and IGT groups ( 1 and 2 ), mean 2-h insulin (Fig. 1D) values were substantially reduced during the intervention period, concomitant with the fall in 2-h glucose, and the reduction was closely related to the development of oxygen uptake and body weight (lower values also being obtained at 0 and $40 \mathrm{~min}$; data not shown), and at follow-up was $30 \%$ lower in Group 1 $(p<0.0001)$ and $31 \%$ lower in Group $2(p<0.0001)$. In the IGT non-randomised reference group (3), there were no significant changes in $2-\mathrm{h}$ insulin values $(-7 \%$; $p=0.43$ ), while fasting values tended to increase (by $27 \% ; p=0.09$, NS). In normal control subjects (Group 4), 2-h insulin values remained essentially unchanged.

Median values for the insulin increment at $40 \mathrm{~min}$ postload (Fig.2) were somewhat (though NS) lower at followup in the Type 2 diabetes group (1), whereas values in the IGT group (2) were unchanged. In contrast, values fell significantly in the IGT non-randomised reference group (3), in which glucose values increased. In normal control subjects whose glucose values were constant, the increment was also unchanged.

\section{Prevalence of Type 2 diabetes and IGT at follow-up (Table 2)}

In the Type 2 diabetes group (1), more than half $(53.8 \%)$ of the participants had improved and were in remission at follow-up (i. e. no longer reached glucose levels diagnostic for diabetes). In the IGT group (2), glucose tolerance had improved in $75.8 \%$ of cases, and was even below a 2 -h value of $7.0 \mathrm{mmol} / \mathrm{l}$ in $52.2 \%$ of cases; $10.6 \%$ of Group 2 had diabetes at follow-up. In the IGT non-randomised reference group (3), glucose tolerance had deteriorated in $67.1 \%$, and diabetes was found in $28.6 \%$. The relative risk

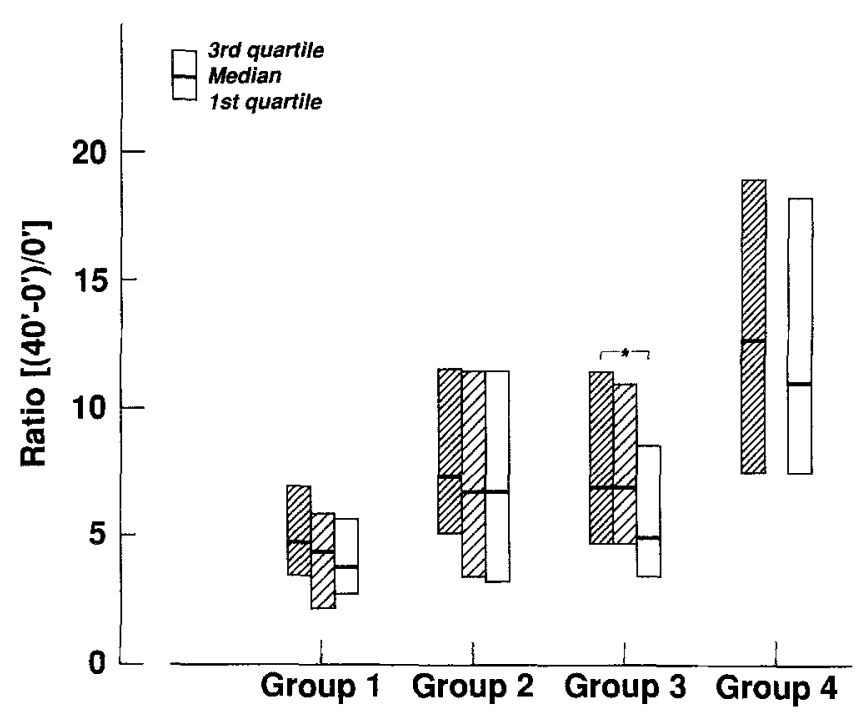

Fig. 2. Insulin increment at $40 \mathrm{~min}$ post-load (ratio (40 min$0 \mathrm{~min}) / 0 \mathrm{~min}$ ) at baseline and at follow-up after 6 years. Group 1 , Type 2 (non-insulin-dependent) diabetic patients (treated), $n=26$; Group 2, impaired glucose tolerance (IGT) subjects (treated), $n=110$; Group 3, IGT subjects (not treated), $n=28$; Group 4, normal control subjects, $n=96$. Absentees at the 6-year follow-up and subjects with incomplete insulin data are excluded. (2nd test at baseline was not performed in Group 4.) $\square$ baseline, 2nd test; $\square$ follow-up; $* p<0.05$ 
of diabetes development in Group 2 compared to Group 3 was 0.37 (95\% confidence interval of $0.20-0.68$, $p<0.003)$. There were no cases of diabetes in the selected normal control group (4).

\section{Development of blood pressure and blood lipids (Table 1)}

Blood pressure was reduced both in the Type 2 diabetes group (1) and in the IGT groups (2 and 3), and more subjects were on antihypertensive medication. The prevalence of medication for hypertension at follow-up was lower in the IGT group (2) than in the IGT non-randomised reference group (3), but diabetes development was unrelated to anti-hypertensive treatment (mainly beta-blocking agents) in both groups ( $\mathrm{Chi}^{2}$ test). In Group 2, a comparable reduction in 2-h glucose values was seen in those on antihypertensive treatment $(n=36)$ and those not $(n=125)$ (mean value of $1.2 \mathrm{mmol} / \mathrm{l}$ vs $1.0 \mathrm{mmol} / \mathrm{l}, \mathrm{NS}$ ).

At follow-up, total plasma cholesterol had fallen significantly in the Type 2 diabetes group (1). Early during the intervention programme, the Type 2 diabetes and IGT groups (1 and 2) manifested a substantial reduction in serum triglycerides that was still evident after 6 years (similar pattern as for 2-h glucose values).

\section{Smoking}

Compared to the remainder of the cohort participating in both screening-programmes $(n=4.949)$, the frequency of smokers was lower in the treatment Groups 1 and 2 $(n=200): 39 \%$ vs $49 \%$ at the first screening $(p<0.01)$ and $28 \%$ vs $39 \%$ at the second screening $(p<0.005)$, whereas there was no difference in the frequency of subjects who stopped smoking. The frequency of smokers in Groups 1 and 2 was similar to that among the previously known cases of diabetes.

\section{Mortality}

Overall mortality in the whole cohort during the 6-year period was $3.3 \%$ ( 230 of 6,956 subjects), or an annual mortality of approximately $0.5 \%$. The relative risk of death in the whole treatment group ( 5 of 222 subjects) compared to the remainder of the cohort ( 225 of 6,734 subjects) was $0.67(95 \%$ confidence interval of $0.28-1.62, p<0.37$, NS). No case of fatal myocardial infarction was found among those continuing the treatment protocol. Considering Groups 1-3 together (Type 2 diabetes group and both IGT groups), accumulated mortality was lower than in the previously non-diabetic remainder of the cohort, $3.7 \%$ (11 of 301 subjects) vs $3.2 \%$ (207 of 6,554 subjects) $(p=0.63 \mathrm{NS})$, but significantly $(p<0.003)$ lower than among the previously known (i.e. before screening) diabetic subjects ( $34 \%$ Type 1 and $66 \%$ Type 2 diabetes), where mortality was $11.9 \%(12 / 101)$.

\section{Discussion}

Probably the most important and novel outcome of the present study was that so large a group of sedentary and overweight middle-aged glucose-intolerant or diabetic subjects successfully participated in a 5-year intervention programme, with a drop-out rate of less than $10 \%$. It should be emphasised that the treatment groups consisted of a fairly representative sample of glucose intolerant subjects in the cohort, and not of a sample of volunteers. During the first 2 years, a high degree of treatment motivation was achieved, irrespective of whether the protocol was followed with a group or individually, and it was during this period that participants improved most. Thereafter participants manifested the normal pattern of age-related changes including seasonal variations, in fact at follow-up the IGT group no longer differed from the normal control subjects in body weight, and even a fairly small but persistent weight loss (mean 3.7-2.3\%, Groups 1 and 2 ) is important for metabolic improvement. It was possible to distinguish the effect of diet and training on body weight found in our previous short-term studies (see below), but the aim of the long-term intervention programme (over 5 years) was to utilise the synergistic effect of diet and training. The triceps skinfold index tended to fall in all groups, probably as a result of general redistribution of body fat with age although the fall was greatest in the IGT group. As body weight increased in the non-treated group (3) and in the normal control group (4), their abdominal fat may have increased. It was possible to increase physical activity to the extent that in about $50 \%$ of cases (both IGT and Type 2 diabetes) physical fitness was still improved after 5 years of treatment and group means increased by $10-15 \%$. The intervention programme was as beneficial to the newly detected asymptomatic Type 2 diabetic subjects as to the IGT subjects, and ability to participate in physical training was essentially comparable in the two categories. These findings suggest that environmental factors (e.g. leisure-time physical activity) are more responsible than genetic factors for the poor physical fitness found in Type 2 diabetic and IGT subjects in this age group $[30,31]$.

Weight reduction and improved fitness were equally correlated to improved glucose tolerance, whereas subjects who both reduced weight and increased oxygen uptake improved most. Results are consistent with our previous short-term (6-12 months) studies in the same cohort $[16,17,19,32]$ of which the present study is a direct continuation. Several other short-term studies of physical training in IGT and Type 2 diabetes have been reported [33-42], with various results for glucose tolerance and oxygen uptake, depending on the age group studied, the duration, type and intensity of the training programme, and the severity of glucose intolerance. In a Swedish study of 48 newly detected 60-year-old diabetic patients [43], very few of whom were suitable for participation in a training programme, only six were able to complete a 2 year programme, and their glucose tolerance remained unchanged. The age of 47 to 49 years would therefore seem to be a favourable cut-off level for detecting enough cases at risk and to initiate or increase the level of exercise 
before the period of life when the risk of coronary heart disease or musculo-skeletal disease starts to increase.

The incidence of diabetes was significantly lower in the IGT group (2), than in the IGT non-randomised reference group (3). Although this difference could be due to selection bias owing to group difference in the risk of diabetes, except for a small difference in baseline blood pressure values, the two IGT groups did not differ in any of the principal variables. In addition, most subjects in the reference group were given advice also beneficial vis-á-vis glucose tolerance (e.g. reduce sodium intake, alcohol consumption and obesity). Moreover, in a randomised IGT control group untreated for 6 months (i.e. during the pilot study), mean glucose tolerance was unchanged though some subjects developed diabetes even at this stage [44].

With a view to preserving or even improving Beta-cell function, efforts to increase insulin sensitivity are of the greatest importance [45]. Although for several reasons insulin data are difficult to interpret [46], a noteworthy finding in this study is the indication that Beta-cell damage, (i. e. loss of early responsiveness to glucose), was reduced or inhibited in the Type 2 diabetes and IGT groups ( 1 and 2) paralleled by a reduction of the total insulin response (i. e. increased insulin sensitivity). This might in part explain both the lower incidence of progression to diabetes in the IGT group (2), as compared to the IGT non-randomised reference group (3) in which decompensation of Beta-cell function may have started, and the high remission rate among the newly detected cases of Type 2 diabetes.

Blood pressure was reduced in both IGT groups ( 2 and 3 ). In the intervention group (2), this could not be explained by the fact that an additional percentage of cases were now on anti-hypertensive treatment, but by nonpharmacological effects deriving from the intervention programme. By contrast to findings in another study [47], in neither of our IGT groups ( 2 and 3 ) did diabetes development differ between those on pharmacological treatment for hypertension and those not. The higher incidence of hypertension in the Type 2 diabetes group (1), as compared to the IGT group (2), is probably a result of their more pronounced obesity ( $7 \%$ higher mean body weight) although comparable weight reduction was achieved.

The predominant effect of intervention (diet and exercise) on lipid metabolism was the reduction of type IV hyperlipidaemia in the IGT group (2) throughout the intervention period, while values for triglyceridesincreased substantially in the IGT non-randomised reference group (3). Although the effect on total cholesterol was small (reduced in Type 2 diabetic subjects (1) but unchanged in IGT subjects (2)), nonetheless the LDL/HDL ratio may well have improved, as was found in a previous short-term study [9].

Contrary to findings reported from other studies [4-6], mortality was lower in the Type 2 diabetes and IGT groups ( 1 and 2) than in the non-diabetic remainder of the total cohort. In fact, not a single case of fatal myocardial infarction was found among those following the protocol. In contrast, mortality was more than three-fold higher in previously known diabetic patients (mainly treated at the diabetes clinic) than in the remainder of the cohort (com- parable results for both Type 1 and Type 2 diabetes), and five times higher than in the Type 2 diabetes group (1). Differences in mortality could not be explained by different changes in smoking habits.

To sum up, ithas beenfound possible toinduce and maintain changes in life-style in a large group of IGT and Type 2 diabetic subjects, in the form of enduring weight-loss, increased long-term physical activity and normalised age-related oxygen uptake. This would seem to prevent or postpone progression to diabetes in IGT subjects and delay metabolic deterioration in diabetic patients. The greatest benefit of intervention may not be improved glucose tolerance per se, but the overall improvement in cardiovascular risk profile, with the possibility of reducing morbidity and mortality in cardiovascular disease. The intervention programme we have used could be carried out on a large-scale community basis, with a much simplified check-up procedure, and with a moderate input of resources.

Acknowledgements. This study was supported by grants from the Enhold Lundström Foundation, the Swedish Diabetes Association, the Nordic Insulin Fund, the Swedish National Association against Heart and Chest Diseases, the Malmö Lioness Club, and the University of Lund.

\section{References}

1. Harris MI (1989) Impaired glucose tolerance in the U.S. population. Diab Care 12: 464-474

2. The Division of Diabetes Translation (1990) Diabetes surveillance, 1980-1987. U.S. Department of Health and Human Services. Atlanta, Centers for Disease Control. Annual report.

3. Wingard DL, Barrett-Connor E, Criqui MH, Suarez L (1983) Clustering of heart disease factors in diabetic compared to nondiabetic adults. Am J Epidemiol 117:19-26

4. Panzram G (1987) Mortality and survival in Type 2 (non-insulindependent) diabetes mellitus. Diabetologia 30: 123-131

5. Head J, Fuller JH (1990) International variations in mortality among diabetic patients: the WHO Multinational Study of Vascular Disease in Diabetics. Diabetologia 33: 477-481

6. Fuller J, Shipley M, Rose G, Jarrett J, Keen H (1983) Mortality from coronary heart disease and stroke in relation to degree of glycaemia: the Whitehall study. Br Med J 287: 867-870

7. Jarrett RJ, Keen H, Fuller JH, McCartney M (1979) Worsening to diabetes in men with impaired glucose tolerance ("borderline diabetes"). Diabetologia 16: 25-30

8. Sartor G, Scherstén B, Carlström S, Melander A, Nordén Å, Persson G (1980) Ten-year follow-up of subjects with impaired glucose tolerance. Prevention of diabetes by tolbutamide and diet regulation. Diabetes 29: 41-49

9. Keen H, Jarrett RJ, McCartney P (1982) The ten-year follow-up of the Bedford survey (1962-1972): glucose tolerance and diabetes. Diabetologia 22: 73-78

10. King H, Dowd JE (1990) Primary prevention of Type 2 (non-insulin-dependent) diabetes mellitus. Diabetologia 33:3-8

11. National Institute of Health (1987) Consensus development conference on diet and exercise in non-insulin-dependent diabetes mellitus. Diab Care 10: 639-644

12. Tuomilehto J (1989) Primary prevention of non-insulin-dependent diabetes mellitus: a dream or reality? In: Alberti KGMM, Mazze R (eds) Frontiers of diabetes research: current trends in non-insulin-dependent diabetes mellitus. Elsevier, Amsterdam, pp $101-115$

13. Bennett PH, Knowler WC (1984) Early detection and intervention in diabetes mellitus: is it effective? J Chron Dis 37: 653-666

14. Consensus Statement (1990) Role of cardiovascular risk factors in prevention and treatment of macrovascular disease in diabetes. Diab Care 13: 53-59 
15. Anonymous (1989) Type 2 diabetes or NIDDM: looking for a better name. Lancet I: $589-591$ (Editorial)

16. Lindgärde F, Eriksson K-F, Lithell H, Saltin B (1982) Coupling between dietary changes, reduced body weight, muscle fibre size and improved glucose tolerance in middle-aged men with impaired glucose tolerance. Acta Med Scand 212:99-106

17. Saltin $B$, Lindgärde $F$, Houston $M$, Hörlin R, Nygaard $E$, Gad $P$ (1979) Physical training and glucose tolerance in middle-aged men with chemical diabetes. Diabetes 28 [Suppl 1]:30-32

18. Lindgärde F, Malmquist J, Balke B (1983) Physical fitness, insulin secretion, and glucose tolerance in healthy males and mild type 2 diabetes. Acta Diabet Lat 20: 33-40

19. Saltin B, Lindgärde F, Lithell H, Eriksson K-F, Gad P (1980) Metabolic effects of long-term physical training in maturity onset diabetes. In: Waldhäusl WK (ed) Diabetes 1979. Proceedings of the 10th Congress of the International Diabetes Federation. Excerpta Medica, Amsterdam, pp 345-350

20. Dishman K (1988) Prescription for exercise adherence. In: Hall LK, Meyer GC (eds) Epidemiology, behaviour change, and intervention in chronic disease. Life Enhancement, Champaign, pp 85-113

21. Eriksson K-F, Lindgärde F (1990) Impaired glucose tolerance in a middle-aged male urban population: a new approach for identifying high-risk cases. Diabetologia 33: 526-531

22. Trell E (1983) Community-based preventive medical department for individual risk factor assessment and intervention in an urban population. Prev Med 12:397-402

23. WHO (1985) Expert committee on diabetes mellitus. Third report. World Health Organization Technical Report, Series No 727. WHO, Geneva, pp 9-13

24. Bitzén P-O, Melander A, Scherstén B (1984) How to screen for diabetes mellitus. Acta Endocrinol 262 [Suppl]: 37-41

25. Carrol JJ, Smith N, Babson AL (1970) A calorimetric serum glucose determination using hexokinase and glucose-6-phosphate dehydrogenase. Biochem Med 4: 171-180

26. Heding LG (1966) A simplified insulin radioimmunoassay method. In: Donato L, Milhaud G, Sirchis I (eds) Labelled proteins in tracer studies. Euratom, Brussels, pp 345-350

27. Edwards DAW, Hammond WH, Healy MJR, Tanner JM, Whitehouse RH (1955) Design and accuracy of calipers for measuring subcutaneous tissue thickness. Br J Nutr 9: 133-144

28. Åstrand I (1960) Aerobic work capacity in men and women with special reference to age. Acta Physiol Scand 169 [Suppl]: 49-92

29. Berntorp K, Eriksson K-F, Lindgärde F (1986) The importance of diabetes heredity in lean subjects on insulin secretion, blood lipids and oxygen uptake in the pathogenesis of glucose intolerance. Diab Res 3: 231-236

30. Lindgärde F, Saltin B (1981) Daily physical activity, work capacity and glucose tolerance in lean and obese normoglycaemic middle-aged men. Diabetologia 20: 134-138

31. Helmrich SP, Ragland DR, Leung RW, Paffenbarger RS (1991) Physical activity and reduced occurence of non-insulin-dependent diabetes mellitus. N Engl J Med 325: 147-152

32. Eriksson K-F, Lindgärde F (1988) Intervention strategy in impaired glucose tolerance - the role of physical fitness. In: Smith U, Eriksson S, Lindgärde F (eds) Genetic susceptibility to environmental factors - a challenge for public intervention. Almqvist \& Wiksell International, Stockholm, pp 75-81

33. Ruderman NB, Ganda OP, Johansen K (1979) The effect of physical training on glucose tolerance and plasma lipids in maturity-onset diabetes. Diabetes 28 [Suppl 1]: 89-92
34. Barnard RJ, Lattimore L, Holly RG, Cherny S, Pritkin N (1982) Response of non-insulin-dependent diabetic patients to an intensive program of diet and exercise. Diab Care 5: 370-374

35. Bogardus C, Ravussin E, Robbins DC, Wolfe RR, Horton ES, Sims EAH (1984) Effects of physical training and diet therapy on carbohydrate metabolism in patients with glucose intolerance and non-insulin-dependent diabetes mellitus. Diabetes 33: 311318

36. Schneider SH, Amorosa LF, Khachadurian AK, Ruderman NB (1984) Studies on the mechanism of improved glucose control during regular exercise in Type 2 (non-insulin-dependent) diabetes. Diabetologia 26: 355-360

37. Trovati M, Carta C, Cavalot F et al. (1984) Influence of physical training on blood glucose control, glucose tolerance, insulin secretion, and insulin action in non-insulin-dependent diabetic patients. Diab Care 7: 416-420

38. Reitman JS, Vasquez B, Klimes I, Nagulesparan M (1984) Improvement of glucose homeostasis after exercise training in noninsulin-dependent diabetes. Diab Care 7:434-441

39. Krotkiewski M, Lönnroth P, Mandroukas K et al. (1985) The effects of physical training on insulin secretion and effectiveness and on glucose metabolism in obesity and Type 2 (non-insulindependent) diabetes mellitus. Diabetologia 28: 881-890

40. Rönnemaa T, Mattila K, Lehtonen A, Kallio V (1986) A controlled randomized study on the effect of long-term physical exercise on the metabolic control in type 2 diabetic patients. Acta Med Scand 220: 219-224

41. Lampman RM, Schteingart DE, Santinga JT et al. (1987) The influence of physical training on glucose tolerance, insulin sensitivity, and lipid and lipoprotein concentrations in middle-aged hypertriglyceridaemic, carbohydrate intolerant man. Diabetologia $30: 380-385$

42. Allenberg K, Johansen K, Saltin B (1988) Skeletal muscle adaptations to physical training in type II (non-insulin-dependent) diabetes mellitus. Acta Med Scand 223: 365-373

43. Skarfors ET, Wegener TA, Lithell H, Selinus I (1987) Physical training as treatment for Type 2 (non-insulin-dependent) diabetes in elderly men. A feasibility study over 2 years. Diabetologia 30: 930-933

44. Malmquist J, Lindgärde F, Eriksson K-F, Johansson E (1982) Plasma insulin and $\mathrm{C}$-peptide in relation to glucose intolerance in middle-aged men. Acta Endocrinol 100: 262-265

45. Reaven GM (1988) Role of insulin resistance in human disease. Diabetes 37: 1595-1607

46. Ferner RE, Alberti KGMM (1986) Why is there still disagreement over insulin secretion in non-insulin-dependent diabetes? Diabetic Med 3: 13-17

47. Skarfors E, Lithell H, Selinus I, Åberg H (1989) Do antihypertensive drugs precipitate diabetes in predisposed men? $\mathrm{Br}$ Med J 298: $1147-1152$

Received: 22 May 1991

and in revised form: 4 September 1991

Dr. K.-F.Eriksson

Department of Internal Medicine

Malmö General Hospital

University of Lund

S-21401 Malmö

Sweden 